\title{
Movimentos participativos e interativos na constituição de educadores ambientais pela pesquisa
}

\author{
Maria do Carmo Galiazzi ${ }^{1}$
}

Resumo: Este artigo faz reflexões sobre ser pesquisador no campo da Educação Ambiental a partir de dois textos: "Um Olhar para a Produção de Pesquisa em Educação Ambiental", do GT Ambiente, Sociedade e Educação da ANPPAS, de autoria de Maria Rita Avanzi, Isabel Cristina de Moura Carvalho e Luiz Antonio Ferraro Jr., e "Educação Ambiental como campo de conhecimento: a contribuição das pesquisas acadêmicas para sua consolidação no Brasil”, de Jorge Megid. As reflexões aqui apresentadas se originaram da coordenação da mesaredonda no V EPEA dos referidos textos e da minha participação no Programa de Pós-Graduação em Educação Ambiental da FURG. O argumento que busco defender é que o pesquisador do campo da Educação Ambiental precisa se entender um educador ambiental se a aposta está na necessária transformação do modelo societário hegemônico, e para isso é preciso ter um pensamento crítico em relação a esse modelo societário. O processo precisa ser mediado pela pesquisa, que é o que se apresenta como contribuição para o campo da Educação Ambiental como modo de intensificar processos de compreensão sobre ser pesquisador e educador ambiental.

Palavras-chave: Pesquisador, Educador Ambiental, Pesquisa.

Abstract: This paper reflects upon being a researcher in the field of Environmental Education. It is based on two texts: "A look at research production in Environmental Education”, written by Maria Rita Avanzi, Isabel Cristina de Moura Carvalho and Luiz Antonio Ferraro Jr., members of the Environment, Society, and Education Working Group at ANPPAS, and "Environmental Education as a field of knowledge: the contribution of academic research to its consolidation in Brazil", written by Jorge Megid. This reflection results from the coordination of a round table at the V EPEA - where the texts were presented - and from my experience as a professor in the Postgraduate Program in Environmental Education at FURG. I contend that the researcher in the field of Environmental Education needs to see him/herself as an environmental educator if $\mathrm{s} /$ he believes the hegemonic model of society has to be changed; therefore critical thinking on this model is an essential point. The process needs to be mediated through research, which is what is presented here as a contribution to the field of Environmental Education as a way to strengthen the processes to understand what it means to be an environmental researcher and educator.

Keywords: Researcher, Environmental Educator, Research.

${ }^{1}$ Licenciada em Química, Mestre e Doutora em Educação. Professora da Escola de Química e Alimentos, Faculdade de Educação, Universidade Federal do Rio Grande FURG. Contato: Av. Itália, s/n, Campus Carreiros - CEP 96201-900 - Rio Grande RS. E-mail: mariagaliazzi@furg.br 


\section{Apresentação}

O texto de Maria Rita Avanzi e colegas mostra a pesquisa em Educação Ambiental na análise dos trabalhos do GT Ambiente, Sociedade e Educação da ANPPAS sendo feita especialmente por mulheres em universidades públicas da região Sudeste do Brasil. A diversidade marca a pesquisa e temáticas emergentes, como a de políticas públicas, são destacadas. O pensamento crítico é o de maior presença, embora em uma polissemia de sentidos. A autora aponta a falta de clareza dos sentidos atribuídos à EA e que esse enfrentamento merece ser encarado por nós, pesquisadores.

Outro aspecto é a pouca presença nos textos de pesquisas do campo teórico da Educação. $\mathrm{O}$ mesmo com relação às metodologias de pesquisa. Pesquisa-ação e pesquisa participante predominam - justamente as que encontram, de certo modo, resistência na academia consolidada. Assim, a autora conclui que, como pesquisadores em Educação Ambiental, estamos inseridos em um contexto mais amplo, multifacetado, marcado por uma pluralidade temática e teórica em que nem sempre nos voltamos para os referenciais teóricos.

Megid, com outro formato de pesquisa, o estado da arte, é contundente em sua análise ao apresentar e descrever a incipiência do campo, seja pela dificuldade de acesso, seja pela ausência de bancos digitais de informação seguros, completos e atualizados. Ressalva precisa ser feita de que não é só condição da Educação Ambiental. O autor acrescenta:

Saber quanto produzimos não é suficiente. É preciso saber da qualidade dessa produção, a consistência científica do conjunto dos trabalhos, a coerência entre propósitos de investigação e delineamentos metodológicos. E sobretudo, temos de conhecer e avaliar a capacidade dessa produção em estudar os problemas ambientais locais e visar à mudança de realidade, em intervir e contribuir na formulação de políticas públicas consequentes e responsáveis no âmbito das questões ambientais, em intervir e produzir uma Educação Ambiental de natureza crítica e emancipatória.

Assim, neste texto defende-se o argumento da necessidade de ensinar a fazer pesquisa por meio de um processo constitutivo de educadores ambientais. Esse processo, por sua vez, deve ser potencializado por outros processos participativos/interativos estabelecidos na ocorrência de uma aula, na qual aprendizes de pesquisa dialogam, investigam, produzem conhecimento enquanto aprendem com educadores ambientais pesquisadores mais experientes, também aprendentes de fazer pesquisa, alcançando nesse processo compreensões mais 
aprofundadas, especialmente sobre o modo de fazer pesquisa nos aspectos em que os autores participantes da mesa mostraram preocupação. O contexto desta aula é o Programa de Educação Ambiental da FURG e a sala de aula é de Metodologia de Pesquisa Qualitativa.

Considerando o que aponta Avanzi e demais autores em seu texto sobre o afastamento do campo da Educação, em movimento de aproximação apresentam-se os pressupostos da prática pedagógica desenvolvida em um programa de pós-graduação em Educação Ambiental. Descreve-se a seguir o processo de planejamento da disciplina, cuja concepção tem caráter interdisciplinar. Ao descreverem-se as atividades e os movimentos inerentes ao processo, incluem-se relatos dos estudantes durante o processo. Os dados apresentados são indicativos do argumento de que é possível inovar, inventar e fomentar o prazer do aprender, do pesquisar, do produzir e do compartilhar conhecimento em uma comunidade aprendente, na qual a participação, o empreendimento mútuo, o engajamento e o repertório compartilhado possam ser características do grupo que junto se constitui como educador ambiental pesquisador.

\section{O complexo e singular evento pedagógico - a aula}

Cada aula é única e sobre esse evento complexo incidem muitos fatores. $\mathrm{Na}$ tentativa de otimizar os movimentos que ali acontecem tendo em vista uma aprendizagem significativa, é fundamental um pensar prévio, um planejamento refletido, que seja discutido coletivamente e constantemente avaliado em direção às reorientações e mudanças necessárias. Aula significa momento da interação cognitiva e afetiva que otimiza as capacidades de olhar, ouvir, imaginar, sentir, expressar-se, avaliar, criticar, argumentar. Nessa perspectiva, Vasconcellos (1999, p. 60) afirma que:

É preciso uma 'temperatura afetiva', uma espécie de 'catalisador do processo de construção do conhecimento', 'aquecer' a relação para que possa ocorrer mais interação: disposição de energias físicas e psíquicas para o ato de conhecer. $\mathrm{O}$ sujeito só aprende dentro de um vínculo afetivo.

Os partícipes do ato pedagógico precisam estar abertos, dispostos a aprender, ligados, conectados entre si e com o objeto de estudo, significando e (res)significando cada etapa do processo de aprendizagem. Nessa rede complexa de múltiplas relações de ordem emocional, cognitiva, pessoal, social e virtual, saberes e não saberes cruzam-se e entrecruzam-se, afeições e desafeições 
perpassam o ambiente, em intervenções que incidem sobre os processos de ensino e de aprendizagem. Nesse sentido, Maturana e Dávila (2005) auxiliam a compreender a aprendizagem, foco da sala de aula, quando afirmam que essa acontece na convivência. E pode para muitos parecer que seja um processo consciente, mas só o que se pode descrever é o que resulta dessa aprendizagem, e assim se configura o mundo em que se vive.

Em verdade, vários são os espaços-tempos nos quais o evento aula ocorre, sendo necessário um pensar sobre cada um deles, otimizando e multiplicando os momentos propícios ao aprendizado. A construção de conhecimentos a partir dos saberes dos alunos, com suporte em estratégias criativas, dialógicas, tecnológicas, todas elas pedagógicas, permite a busca e a reconstrução criativa do conhecimento em processos múltiplos de aprender.

Mesmo considerando a imprevisibilidade e singularidade de cada situação de ensino e aprendizagem, planejar, projetar cada momento da aula permite um recriar prévio do ato pedagógico que se pretende que seja mobilizador de energias, acolhedor e interativo. É preciso compartilhar, discutir o planejamento no primeiro encontro entre os atores da aula para que se estabeleça um processo de cumplicidade e desejo de aprender coletivamente. Importa que o professor explicite, em suas ações, suas intenções. Mais do que isso, precisa evidenciar seu entusiasmo e sua paixão pelo ofício, assegurando também a predisposição dos envolvidos no processo para a escuta, para o acolhimento e respeito às diferenças. Na mescla de sentimentos e saberes, a aprendizagem ocorre de forma mais significativa e profunda. Isso está presente na formação de pesquisadores? É o que se pretende apresentar a seguir.

\section{O tempo de sol e mar quente: o pensar antes do encontro}

No entendimento de que cada aula é única, singular e deve estar conectada com as questões cotidianas, com o desejo e a disposição de todos os envolvidos para aprender, e não reduzida a um momento fortuito na vida dos estudantes, planejam-se os encontros da disciplina Metodologia da Pesquisa em Educação I, do Programa de Pós-Graduação em Educação Ambiental, da Fundação Universidade Federal do Rio Grande (RS), alguns meses antes do início do período letivo, em pleno verão. E toma-se como referência Anastasiou (2006, p. 81): a interação intencional, planejada e responsável dos estudantes com o professor e o objeto de conhecimento configura a essência da relação pedagógica. Mediada pelo conhecimento, essa relação busca o alcance da lógica própria das diversas áreas, numa construção inovadora, mobilizando o envolvimento e o comprometimento dos sujeitos estudantes e professores, no 
processo de compreensão da realidade e do campo profissional, compartilhando os saberes e os sabores.

É impossível desconsiderar a importância dada ao planejamento, pois é ele que permite ver a intenção de nossas perguntas. Entendendo a aula como espaço dialógico por excelência, o estudante precisa, como parceiro nos processos de ensinar e de aprender, perceber quais as nossas intenções nos diálogos propostos. É a Maturana (1998, p. 12) que se recorre para fortalecer esse argumento: “Acho que não se pode considerar nenhuma pergunta sobre os afazeres humanos, no que diz respeito ao seu valor, à sua utilidade ou àquilo que se pode obter deles, se não se explicita o que se quer".

A partir da convicção de que uma boa aula requer o uso de ferramentas pedagógicas variadas e adequadas, os objetivos são traçados, a bibliografia é selecionada e o Ambiente Virtual de Aprendizagem (AVA) é criado. A ideia é que a sala de aula seja apenas um ponto de partida e de chegada das discussões em roda, momento em que se dialoga sobre as dúvidas, acolhem-se as ansiedades, reorganizam-se os trabalhos de pesquisa, dividem-se as tarefas. A sala de aula também se constitui em espaço privilegiado para as apresentações orais, dramatizações e leituras compartilhadas. $O$ uso da tecnologia provoca transformação na compreensão do ato educativo e da postura pedagógica tanto das professoras quanto dos pesquisadores principiantes, não sendo apenas um adereço ou um complemento visando à atualização de procedimentos didáticopedagógicos. O uso do ambiente virtual como ferramenta constitutiva do educador ambiental possibilita uma maneira diferente de organização da aula, que se converte em um espaço-tempo de registro, diálogo, reflexão, acompanhamento e avaliação das atividades desenvolvidas na disciplina.

O objetivo é que esse espaço-tempo seja vivido como um exercício de pesquisa, em que as atividades propostas tenham configuração semelhante às atividades de um pesquisador constituído (GALIAZZI, 2003). Esse objetivo está alicerçado na convicção de que a aprendizagem é uma ação que acontece com o outro, o que se articula ao pensamento de Bauman (2000, p. 143) quando este, ao falar de aprendizagem, traz o pensamento de Margaret Mead:

A estrutura social de uma sociedade e a maneira em que está estruturada a aprendizagem, a maneira em que passa de mãe à filha, de pai a filho, de tio ao filho da irmã, do xamã ao noviço, dos especialistas mitológicos ao aspirante, determina muito além do conteúdo real da aprendizagem, como aprenderam os indivíduos a pensar e como se comparte e se usa a reserva de conhecimento, a soma total de pedaços distintos de habilidade e conhecimento. 
A intenção é que os alunos estejam intensamente conectados no fazer pesquisa, de semana a semana, em cada encontro presencial. Assuntos veiculados na sala de aula devem estar presentes em um continum e as discussões iniciadas em aula devem ser prolongadas, ampliadas, aprofundadas no AVA e em outros espaços. A rede informatizada pode proporcionar o desenvolvimento da capacidade reflexiva e crítica em processos criativos, desde que seu uso seja organizado nessa direção. Encontra-se ressonância dessa intenção em Assmann (2000, p. 235), na ideia de que criar situações propícias ao aprendizado exige que a questão da temporalidade institucional seja observada a fim de situar os atores do ato pedagógico em um tempo circunscrito, essencialmente pedagógico e que não se refere apenas à temporalidade cronológica, mas a múltiplos e diferentes tempos inerentes ao desenvolvimento curricular.

A preocupação do autor vai ao encontro do fato de que a dimensão temporal do processo de aprendizagem não se refere apenas ao tempo cronológico, mas a uma pluralidade de tempos que, literalmente, está em jogo no cotidiano da vivência curricular.

O Programa de Pós-Graduação em Educação Ambiental tem um caráter interdisciplinar, sendo os pós-graduandos provenientes de variadas áreas, o que garante a interação de múltiplas subjetividades, ideias, concepções, experiências. $\mathrm{Na}$ concepção e escolha de estratégias de ensino e de aprendizagem, de bibliografia e de outros materiais, se tem sempre, como foco, a heterogeneidade dos alunos, compactuando com o pensamento de Veiga (2001, p. 148), que afirma: "Uma relação, no cotidiano da aula, é construída da ótica da heterogeneidade, que desvela as diferenças sociais, os conflitos, as contradições. É, portanto, uma relação fundada na diversidade e na construção de identidades".

Em verdade, esse é o diferencial e a riqueza que impregna a proposição aqui apresentada com a intenção de contribuir para preencher as lacunas apresentadas pelos colegas pesquisadores em seus textos.

\section{Os argonautas em navegação}

Compartilhar o desejo da aventura de aprender e dividir as incertezas do caminho a ser percorrido sobre fazer pesquisa é fundamental para que pesquisadores entrem em sintonia. No primeiro dia de aula, os pós-graduandos se apropriam do nome escolhido para esse espaço-tempo de formação: argonautas, em uma relação simbólica com a mitologia grega. A intenção, ao atribuir-se esse nome mitológico aos participantes dessa experiência pedagógica, é todos imbuírem-se do espírito aventureiro dos helenos por mares 
desconhecidos, aprendendo a navegar. Pretende-se estabelecer a ideia de aprender juntos a ser educadores ambientais pesquisadores.

Como o objetivo da disciplina é a constituição de educadores ambientais por meio da pesquisa, os alunos se lançam à pesquisa como intrépidos argonautas, enfrentando dificuldades, mas com o prazer da busca e da construção de saberes. Embora reconhecendo o caráter bélico presente na metáfora assumida, o que se ressalta na história é a participação, seu caráter de coletivo de pessoas com um objetivo: aprender a ser educador ambiental pesquisador.

A proposta para a segunda aula é a apropriação do ambiente virtual de aprendizagem - o AVA. O intuito é perceber a possibilidade de interagir nesse ambiente de várias formas. No AVA, as ações de cada um são itinerantes e todos podem, em um dado momento, assumir a liderança e provocar as discussões junto ao grupo. O conhecimento é construído em grupo pelas professoras e pelos alunos, de forma interativa e colaborativa. De acordo com Freire (1987), tanto o educador como o educando são sujeitos no ato de desvelar a realidade, de conhecê-la de forma mais profunda e crítica, (re)criando o conhecimento, o que fortalece o argumento da sala de aula em que se aprende.

Textos, projetos, exercícios de escrita reflexiva e outros materiais são colocados à disposição no ambiente para estudo, análise, intervenção e avaliação, auxiliando o acesso.

Além disso, no início do semestre, debatem-se questões relacionadas ao processo avaliativo, estabelecendo-se como objetivos: exercitar a expressão escrita; desenvolver a capacidade de argumentação e análise crítica; desenvolver processos de pesquisa; problematizar a visão de ciência; compreender o processo de pesquisa em seus fundamentos éticos, metodológicos e epistemológicos.

Algumas atividades da disciplina são valorizadas: a) presença nos encontros presenciais; b) exercício de escrita quinzenal, no AVA, envolvendo textos crítico-reflexivos sobre a constituição pessoal como educador ambiental; c) autoavaliação; d) heteroavaliação; e) projeto - todos os alunos devem elaborar três versões de seus projetos de pesquisa, sendo duas analisadas por um colega e a versão final pelas professoras. A discussão sobre metodologia de pesquisa qualitativa termina com a apresentação do projeto no evento anual organizado pelas autoras: Seminário de Pesquisa Qualitativa, em parceria com outros programas de pós-graduação da FURG e com a Faculdade de Educação da UFPEL.

No exercício de escrita, a reflexão sobre cada momento do processo de aprendizagem possibilita não somente o desenvolvimento da expressão escrita, tão necessária à pesquisa, mas também favorece a tomada de consciência dos 
alunos da sua constituição como educadores ambientais. Isso encontra suporte em Bruner (2003), mais especificamente em seu argumento de que é preciso instaurar, nos cenários educativos, a emergência da narrativa como constituição de seres que falam e argumentam, que constroem pontos de vista, que "definem situações" assim como concebem os interacionistas simbólicos, como seres conceituais, enfim.

Muitas reflexões dos participantes apontam uma desacomodação, uma desestabilização, um questionamento de saberes do senso comum arraigados, bem como a superação de incertezas:

Decorridos alguns dias do começo da disciplina (e não são tão poucos dias assim), pensar sobre as expectativas iniciais e compará-las com as atuais me faz perceber um turbilhão de pensamentos e sensações ainda tão desconectados quanto antes. As inquietações iniciais eram muitas e continuam sendo. As leituras, informacões e discussões chegam como "chuva sobre terra seca". Aos poucos essas inquietudes comecam a ser filtradas e separadas, mas surgem novas inquietações. Penso que tenho muito a crescer enquanto pesquisador iniciante.

Para alguns pós-graduandos nem sempre fica muito claro o objetivo de a escrita ser proporcionada e intensificada nesse movimento quinzenal, mas, estando sempre presente, ela se desenvolve, como um deles registra:

Aqui estou, no limite entre o mundo que me acolhe e o próximo passo. $\mathrm{Na}$ expectativa e na obrigação de me colocar em movimento, por meio da leitura e da escrita. Movimento que transita entre o prazer e a dor. Nesse momento mais prazer. Mesmo no início dessa expedição, com muitos desafios a enfrentar, me sinto infinitamente feliz em retomar um caminho que havia deixado para trás. O ingresso no mestrado intensifica, novamente, o sentimento de esperança. Não aquela esperança de menina. Uma outra esperança, que causa inquietude, necessidade de busca. Não busca de verdades, mas de possibilidades.

Escrever sobre como venho me constituindo como pesquisadora em Educação Ambiental. Este é o desafio que me move. Pensamentos desordenados surgem na minha mente. Sensacõos múltiplas se farem presentes: desejos, questionamentos, expectativas. Em meio a este turbilhão o acolhimento acontece. Acolbimento de colegas, professores e orientadores que me fazem sentir parte do Programa de Pós-Graduação em Educação Ambiental.

A constituição, processo nem sempre fácil, vai acontecendo, mas o tempo cronológico, muito diferente do tempo humano para constituir-se, pressiona: 
O relógio teima em correr. O tempo passa rápido demais. Cada minuto parece um segundo quando se tem presa. Tenho a sensação de estar viajando nessa expedição na velocidade da luz. Pergunto-me: o que posso fazer para que meu tempo renda mais? Quais são minhas prioridades? Como devo organizar-me?

Percebo que estou me constituindo como pesquisadora em Educação Ambiental porque o meu olhar mudou, porque a minha percepção de caminhada mudou, a minha metodologia está sendo revista e portanto o pronto está sendo repensado. Quem sabe até recomeçado!

A crítica, componente constitutiva na pesquisa, geralmente ingênua no início do processo educativo, estabelece seus contornos:

Se me avalio de maneira positiva, estendo essa avaliação às professoras da disciplina e à proposta que foi idealizada. Se tivesse que pontuar o momento que mais marcou a minha formação até o momento, seria sem dúvida a leitura feita pela professora Maria do Carmo da primeira versão do meu projeto. Argonauta rebelde essa! Desestabilizou-me completamente e desencadeou a minha primeira reunião com a professora para avaliar o mesmo. Claro, inicialmente não foi fácil aceitar a crítica, na realidade nunca é, mas, como uma tripulante dessa nave desbravadora, me permiti assumir novos rumos. Que bom!!!!!

Dentro de tudo isso que relatei, fazer parte da desbravadora turma de Argonautas foi uma experiência no minimo acolhedora, pois é quando falamos de metodologia que os nossos conflitos internos se tornam mais evidentes e assustadores, neste sentido, penso que compartilhar os nossos conflitos é formador. A disciplina nos propõe também a uma entrega disciplinada às tarefas propostas e um momento de profunda reflexão sobre o nosso "objeto", metodologia e fundamentação teórica, promovido na necessidade de reescrever o projeto em três versões. Na realidade, a cada avaliação do projeto se desencadeia uma nova crise. E que bom que entramos nela!

E a ansiedade inicial vai sendo administrada como característica inerente a se tornar pesquisador, como descrito no relato a seguir:

Hoje bem mais tranquila, percebo que ser pesquisadora é um processo em que vamos nos constituindo como uma obra de arte, nos transformando a cada leitura e escrita realizada. Também percebo conversando com colegas o quanto é normal esta ansiedade para realizar a escrita do projeto, as decisões que devem ser tomadas em relação ao objeto de pesquisa, sobre o qual ainda não tenho muita conviç̧ão.

E que ansiedade para apresentar o trabalho sobre teorias compreensivas, sou professora há tanto tempo, mas que sensação diferente de apresentar para os colegas, ainda bem que tinha mais colegas assim. 
Penso que um dos meus dilemas é enxergar meu problema de pesquisa, mas os diálogos de boje à tarde me possibilitaram a reflexão sobre essa questão. E também pensar sobre a importância do aprender com outro, em roda de formação.

Nessa roda as pesquisas vão se entrelaçando umas com as outras e o compartilhamento de saberes favorece uma aprendizagem muito significativa, não esquecendo do amendoim, rapadura e chimarrão, que rolava enquanto conversávamos, foi muito legal.

Pesquisadores críticos sobre o trabalho acadêmico pincelam atitudes coerentes com um pensar produtor de conhecimento como o requerido para o pensamento científico:

Nesta fase de meu processo de investigação estou muito imerso no estudo de conceitos que serão a base teórica de minha pesquisa. Conceitos que perpassam a concepção de Ontologia de Georg Lukács, a partir dos quais busco fundamentar minha argumentação sobre a origem das relações do homem com a natureza, e mais, a própria concepção de natureza bumana. Por outro lado, me inquieta pensar que a busca de conceitos em uma teoria não pode servir apenas como mera ilustração, ou pior, como uma mera roupagem de uma pseudo-erudição que se basta a si mesma. Verborragia intelectual.

Cumpre salientar que todas as atividades planejadas, tanto para os momentos presenciais quanto para os virtuais, são interligadas e objetivam promover a conexão, o ligar-se, o envolver-se com a matéria desenvolvida. A mediação das tecnologias é fundamental para o alcance desses objetivos.

\section{A pesquisa coletiva}

Outro aspecto relevante no desenvolvimento da disciplina é a pesquisa coletiva: $A$ constituição de educadores ambientais pela pesquisa, a qual objetiva investigar a constituição de educadores ambientais pela pesquisa em sua formação, enquanto pesquisadores do Programa de Pós-Graduação em Educação Ambiental da FURG.

Tal processo iniciou um programa de pesquisa que objetiva, por um lado, contribuir para a formação de cada educador ambiental pesquisador, considerando que na experiência é que ele aprende, e, por outro, a partir dos resultados desta pesquisa, fornecer subsídios e argumentos com vistas à implementação de ações educativas mais efetivas - caso necessário, pelo próprio PPGEA - para a intensificação da compreensão sobre processos de fazer pesquisa requeridos pela comunidade científica. 
A continuidade da pesquisa em diferentes semestres tem a intenção de possibilitar o encontro entre pesquisadores iniciantes com seus colegas mais experientes, via mecanismos de análise e produção de significados, tais como entrevistas, análise das dissertações, e também com pesquisadores experientes, como os orientadores.

A razão de investigar esse problema foi a emergência recente do campo da Educação Ambiental aliada à fluidez da constituição da área. Articulada a esse motivo, está outra razão educativa importante: a instabilidade do próprio termo "educador ambiental" para pesquisadores iniciantes, uma vez que eles próprios adentram e intensificam o campo teórico-prático da Educação Ambiental pela pesquisa e, no momento de chegada ao mestrado, não têm clareza do significado de ser educador ambiental. Ou seja, o limite da Educação Ambiental está sempre em movimento de criação, a partir dos sujeitos que a constituem também. Nessa perspectiva, a pesquisa desenvolvida pretende contribuir para a construção de educadores ambientais de forma mais consistente, possibilitando assim a emergência de identidades profissionais mais demarcadas e complexas.

Assim é a pesquisa coletiva desenvolvida na sala de aula dos argonautas, pois, como salientado, o fenômeno investigado pode ser transformador, na medida em que a pesquisa coaduna-se com o entendimento da aprendizagem como um movimento de imersão em um campo de conhecimento. A partir de ações menos intensas, ocorrem aprendizagens pela intensidade e envolvimento nessas ações e, nesse processo, o aprendiz aprende o ofício (LAVE; WENGER, 1991). Também se pode atribuir à pesquisa desenvolvida o cunho de pesquisaação (MINAYO, 2007), uma vez que os pesquisadores pertencem à comunidade investigada e a transformação pretendida é a da própria constituição do pesquisador.

Inicia-se o trabalho de pesquisa procedendo-se à análise dos títulos e dos resumos das mais de cem dissertações produzidas em nosso programa, mas os resultados do próprio PPGEA, em termos de produção teórica e de comunidade de pesquisadores envolvidos, mostram que são inúmeras as circunstâncias e os focos a serem analisados, como entrevistas, dissertações, teses e artigos de educadores ambientais do PPGEA.

Como recém-mencionado, o primeiro objeto de análise têm sido os resumos de dissertações produzidas até o momento. Com base nos resumos, desenvolve-se um exercício de análise textual discursiva, como proposto por Moraes e Galiazzi (2007), a qual consiste em um processo de produção de significados sobre o fenômeno investigado a partir da sistematização de procedimentos que podem ser sintetizados em: unitarização das informações 
obtidas, categorização dessas informações e produção de sínteses compreensivas de acordo com as questões de pesquisa.

Nesse processo, os argonautas ficam atentos às palavras e aos diferentes significados atribuídos à configuração da Educação Ambiental e do educador ambiental pela pesquisa, especialmente nos títulos e resumos das dissertações. Considerando o resumo como a porta de entrada e convite à leitura de uma dissertação ou tese, entende-se que esse deve ter clareza e objetividade e explicitar os argumentos desenvolvidos na pesquisa. Da mesma forma, o título precisa ser sucinto, contendo indicadores do trabalho realizado. No processo de análise descrito, procura-se então destacar a necessidade de um título informar o que foi pesquisado. A diversidade de formas de sintetizar a pesquisa apareceu em descrições e argumentos.

A análise dos títulos, mesmo que exploratória, também é um indicativo desse processo de constituição, pois durante a aula em que se realiza esse exercício evidenciam-se formas diferentes de perceber e fazer pesquisa. Também se nota, pela visualização dos próprios títulos, que a compreensão do que é ciência nem sempre está clara para o pesquisador em razão do exposto no título, pequena mas importante parte do trabalho muitas vezes negligenciada de uma pesquisa, e a sua importância reside no fato de que por ele se torna concreta a possibilidade de interlocução.

O exemplo denota a hipótese de trabalho de que fazer pesquisa sobre como o educador ambiental se constitui contribui para a constituição do mesmo. Outro aspecto a ressaltar nesse projeto são as categorias de análise, sejam elas $a$ priori ou emergentes na pesquisa. E, embora não haja prática sem teoria, o que se pretende é que as categorias e os teóricos a validar o conhecimento produzido sejam emergentes do processo de pesquisa. Com isso não se está dizendo que as teorias de suporte ao trabalho tenham que se originar na pesquisa em processo, mas que o processo de pesquisa vai exigir que se adentre uma teoria ou outra, em razão das categorias produzidas.

Concomitantemente às atividades realizadas na sala de aula e no AVA, a leitura de textos e livros é compartilhada, discutida e articulada aos conteúdos desenvolvidos. Todos os canais objetivam o partilhar de ideias e de ansiedades, que o próprio processo de aprender provoca, e a valorização de cada um dos atores por meio das vozes multiprofissionais dos argonautas. De acordo com Freire (1997, p. 135): "Escutar é obviamente algo que vai mais além da possibilidade auditiva de cada um". Escutar implica respeito às singularidades, aos limites, ao ritmo próprio, às diferenças, às subjetividades expressas em cada momento do processo de ensino e aprendizagem. 


\section{O Seminário de Pesquisa Qualitativa: fazendo metodologia}

O momento culminante de discussão sobre metodologia de pesquisa é a organização e a execução do Seminário de Pesquisa Qualitativa, o qual se configura como atividade integradora do espaço-tempo de discussão. Esse seminário caracteriza-se como um espaço-tempo de discussão de diferentes possibilidades metodológicas na pesquisa qualitativa. É dirigido a acadêmicos de graduação, de pós-graduação e pesquisadores que têm, em seus trabalhos, a pesquisa qualitativa como um de seus pressupostos e é realizado em parceria com a Universidade Federal de Pelotas, RS. Tem por objetivos: discutir abordagens metodológicas de pesquisa qualitativa, divulgar possibilidades da pesquisa qualitativa contemporânea e potencializar comunidades de aprendizagem em pesquisa qualitativa.

Os argonautas apresentam, durante o seminário, a última versão dos seus projetos de pesquisa nos Grupos de Discussão, juntamente com os demais pesquisadores inscritos. O seminário também tem uma proposta que se coaduna com os pressupostos salientados na organização da aula aqui descrita. Ou seja, o próprio seminário é considerado um momento integrante do espaço-tempo de Metodologia de Pesquisa I e os pesquisadores iniciantes escrevem seus trabalhos, leem os trabalhos dos colegas, discutem todos os trabalhos de um grupo em uma das manhãs do evento. Nos outros turnos, os participantes envolvem-se com aspectos consagrados da vida de um pesquisador, quais sejam: a palestra de um pesquisador experiente e a participação em Grupos de Pesquisa coordenados por pesquisadores experientes ou em Grupos de Trabalho sobre alguma metodologia específica.

A experiência vivida pelos argonautas tem propiciado ao longo dos anos não somente alavancar o processo de constituição dos pós-graduandos em pesquisadores/educadores ambientais, mas a instauração, no próprio momento do trabalho interdisciplinar, da reflexão contínua e constante, por parte das professoras, de uma prática pedagógica que necessita ser proativa e provocadora, participativa e integradora da diversidade dos sujeitos do processo educativo. Nesse espaço-tempo planejado, construído, experienciado coletivamente, é estabelecida uma rede formativa, participativa, comunicativa e afetiva, facilitadora da interlocução e da aprendizagem.

A partir dessa prática de formação de educadores ambientais pela pesquisa é que se presume poder preencher as lacunas apresentadas em textos de pesquisas e, ao mesmo tempo, contribuir para a constituição de pesquisadores que pertencem ao campo da Educação Ambiental, que se entendam educadores 
ambientais e que, com diferentes enfoques teóricos, tenham um posicionamento político para se contraporem ao modelo societário vigente.

\section{Referências}

ANASTASIOU, Léa das Graças Camargo. Avaliação, ensino e aprendizagem: anotações para ações em currículo com matriz integrativa. In: ENCONTRO NACIONAL DE DIDÁTICA E PRÁTICA DE ENSINO, 13., 2006. Recife. Anais... Recife: UFPE, 2006. p. 213-242.

ASSMANN, Hugo. Reencantar a educação: rumo à sociedade aprendente. 8. ed. Petrópolis: Vozes, 2004.

BAUMAN, Zygmunt. La sociedad individualizada. Madrid: Cátedra, 2000.

BRUNER, Jerome. The culture of education. 7. ed. United States of America: Library of Congress Cataloging-in-Publication Data, 2003.

DEMO, Pedro. Pesquisa e construção do conhecimento: metodologia científica no caminho de Habermas. Rio de Janeiro: Tempo Brasileiro, 1997.

. Pesquisa qualitativa: busca de equilíbrio entre forma e conteúdo. Rev. Latino-Am. Enfermagem, Ribeirão Preto, v. 6, n. 2, p. 89-104, abr. 1998. Disponível em: $<$ http://www.scielo.br/scielo.php?script $=$ sci_arttext\&pid $=$ S0104-

11691998000200013\&lng=en\&nrm=iso >. Acesso em: 04 nov. 2007.

FREIRE, Paulo. Pedagogia do oprimido. 17. ed. Rio de Janeiro: Paz e Terra, 1987.

. Pedagogia da autonomia. Saberes necessários à prática educativa. 2. ed. São Paulo: Paz e Terra, 1997.

GALIAZZI, Maria do Carmo. Educar pela pesquisa: ambiente de formação de professores de Ciências. Ijuí: UNIJUÍ, 2003.

GOODSON, Ivor. Currículo, narrativa e futuro social. Trad. Eurize Caldas Pessanha e Marta Banducci Rahe. Revista Brasileira de Educasaão, Campinas, v. 12, n. 35, p. 241-252, maio/ago. 2007.

LAVE, Jean; WENGER, Etienne. Situated Learning: Legitimate Peripheral Participation. Cambridge: Cambridge University Press, 1991.

MATURANA, Humberto. Emoções e linguagem na educação e na política. Belo Horizonte: UFMG, 1998.

MATURANA, Humbeto; DÁVILA, Ximena. Educación desde la matriz biológica de la existencia humana: Biología del conhecer y Biología del amar. Chile, 2005. Disponível em: $<$ www.unesco.cl/medios/biblioteca/documentos/sentidos_educacion_ponencia_humbe rto_maturana_ximena_davila.pdf $>$. Acesso em: 04 nov. 2007.

MINAYO, Maria Cecília. Os desafios do conhecimento. São Paulo: Hucitec, 2007. 
MORAES, Roque. Mergulhos discursivos. In: GALIAZZI, Maria do Carmo; FREITAS, José Vicente. Metodologias Emergentes de Pesquisa em Educação Ambiental. Ijuí: UNIJUÍ, 2005.

MORAES, Roque; RAMOS, Maurivan Güntzel; GALIAZZI, Maria do Carmo. A epistemologia do aprender no educar pela pesquisa em Ciências. In: MORAES, Roque; MANCUSO, Ronaldo (Org.). Educação em Ciências: produção de currículos e formação de professores. Ijuí: UNIJUÍ, 2004. p. 87-134.

VASCONCELLOS, Celso. Construção do conhecimento em sala de aula. 6. ed. São Paulo: Libertad, 1999.

VEIGA, Ilma Passos Alencastro. O cotidiano da aula universitária e as dimensões do projeto político-pedagógico. In: CASTANHO, Sérgio; CASTANHO, Maria Eugênia (Org.). Temas e textos em metodologia do ensino superior. Campinas: Papirus, 2001. (Coleção Magistério: Formação e Trabalho Pedagógico).

Artigo: recebido em 12/11/2009 - aprovado em 21/12/2009 